\title{
Filigrane
}

Écoutes psychothérapiques

\section{Le vieillissement du psychanalyste. Témoignage}

\section{Jacqueline Prud'homme}

Volume 18, numéro 1, printemps 2009

Le corps. Sur le divan. Dans le fauteuil I

URI : https://id.erudit.org/iderudit/037724ar

DOI : https://doi.org/10.7202/037724ar

Aller au sommaire du numéro

Éditeur(s)

Revue Santé mentale au Québec

ISSN

1192-1412 (imprimé)

1911-4656 (numérique)

Découvrir la revue

Citer ce document

Prud'homme, J. (2009). Le vieillissement du psychanalyste. Témoignage.

Filigrane, 18(1), 96-98. https://doi.org/10.7202/037724ar d'utilisation que vous pouvez consulter en ligne.

https://apropos.erudit.org/fr/usagers/politique-dutilisation/ 


\section{Le vieillissement du psychanalyste. Témoignage ${ }^{1}$ jacqueline prud'homme}

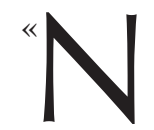

e cherchez pas à vivre éternellement», disait Bernard Shaw, vous n’y arriverez pas. L'inconscient étant intemporel, nous n'y croyons pas.

Mon vieillissement comme analyste et comme personne qui entre dans la vieillesse objective, j'aurai 80 ans l'an prochain, contredit mon sentiment subjectif d'être encore jeune. Le vieillissement demande un énorme travail d'élaboration. Même si je me sens jeune, je ne peux ignorer les petites défaillances du corps qui se manifestent sournoisement comme autant de clins d'œil m'avertissant du début du déclin. Mon sentiment de toute puissance dénié jadis :

«C'est un métier merveilleux, je pourrai le pratiquer jusqu'à ma mort », c'està-dire à jamais, s'étiole.

La mort, la finitude existent. Je sais maintenant d'une certitude intérieure qu'un jour, je mourrai à mon tour, même si parfois je l'oublie. De cette même certitude, que je ne serai jamais longue et mince avec les cheveux noirs, raides, relevés en chignon; mais il y a toujours le déni qui guette.

Par ailleurs, je sais, je sens aussi que la libido, Eros, est toujours vivant. Je me souviens de Clifford Scott, que j'étais allée voir après la mort de mon analyste, qui m'avait demandé, après m'avoir offert un siège: «Do you want to live until you die ?». Je n'ai jamais oublié sa question et y repense souvent.

Ma mère, qui était une femme très vivante pleine de dictons et de proverbes, m'avait dit un jour à un âge avancé : «Tu sais, ne t'en fais pas, vieillir n'est pas si difficile, on perd tout doucement sans s'en apercevoir le goût de certaines choses qui sont remplacées par d'autres. Ce qui est triste, par ailleurs, disait-elle, c'est que l'on ne se sent pas vieillir, on ne se sent pas vieux, mais quand on se regarde dans le miroir, on voit les ravages du temps : c'est le corps qui vieillit. »

Elle parlait d'investissement, de déplacement des investissements, d'âge objectif, d'âge subjectif, des défaillances du corps, de perte, de détachement et de deuil.

Si j'ai accepté d'aborder ce thème, c'est que je suis dans le processus de vieillissement, que j'essaie de l'apprivoiser et de l'élaborer depuis un certain temps déjà, et me demande quel est son impact sur mon travail clinique. Mon oreille droite est moins fine, j'ai moins d'endurance à la fatigue et il m'arrive d'avoir des endormissements l'après-midi si je ne me couche pas assez tôt la veille de mes journées de travail. J'ai parfois des distractions en séances et quelques fois un vague sentiment d'avoir suffisamment travaillé et rêver de ne rien faire. 
J'ai lu avec intérêt certains articles sur le sujet: Freud, Quinodoz. Denis, Ribas, ce qui m'a amené à réfléchir à mon expérience d'analyste vieillissante et à me souvenir de moi, jeune analyste, de voir ce que j'étais et ce que je suis devenue.

Je suis venue tardivement à l'analyse. J'avais déjà une longue et solide formation en thérapie familiale et conjugale, une formation en gestalt thérapie et en thérapie de groupe, dans le courant de la psychologie humaniste existentielle, après une expérience malheureuse en psychanalyse.

Bien que toutes ces formations aient été extrêmement précieuses, j'avais toujours l'impression qu'il me manquait quelque chose d'essentiel pour arriver à comprendre les paradoxes mortifères que vivent certains couples et certaines familles. Comme sur le plan personnel je sentais une angoisse récurrente, je décidai de risquer à nouveau une psychanalyse. Malheureusement, mon analyste est mort en cours de route. Sa façon de faire face à sa maladie, à sa mort et à ses analysants, dans les circonstances, reste pour moi un exemple à suivre... Ensuite, j'ai continué mon chemin avec un autre analyste.

Quand j'ai découvert la psychanalyse, j'ai découvert le Pérou. J'ai trouvé ce que je cherchais à comprendre et je me suis trouvée.

Je suis devenue une inconditionnelle de la psychanalyse. Elle me passionnait, je voulais en connaître davantage et, à mon tour, pouvoir la pratiquer. Mon désir était soutenu par mon analyste. Alors, quelle déception d'être refusée à la société de psychanalyse !

Ma première demande a échoué avec son cortège de questionnement, d'angoisse, de doute et même un sentiment de scandale ! Pourquoi ? Comment? Puis, j'ai continué à creuser, à me questionner et, comme je suis tenace, que j'avais l'appui d'autres analystes, que je ne voulais pas abandonner mon désir, j'ai tenu bon et j'ai pu enfin avoir accès à la société.

J'étais jeune, j'avais la passion de l'analyse ; j'avais la foi en la psychanalyse, une curiosité pour l'appareil psychique, l'organisation complexe et subtiles des défenses, la notion de conflit et la paradoxalité.

J'avais de la compassion, de l'empathie pour la souffrance des autres, n'étant pas loin encore de la mienne. M'étant découverte grâce à l'analyse, je ne voyais pas pourquoi les autres ne le pourraient pas.

J'étais convaincue que la psychanalyse était pour tout le monde, que seule celle-ci pouvait faire advenir un sujet, soulager, réparer, guérir même! Et si ça ne marchait pas, il fallait regarder du côté de l'analyste.

Bref, l'analyse était idéalisée, elle était toute-puissante, et moi aussi par le fait même, mais cela, je ne le savais pas encore.

Je suis certaine maintenant que cette fougue, cette idéalisation et le sentiment, la croyance, que si je savais attendre, si j'établissais et maintenais un cadre, si je savais contenir et aussi interpréter à bon escient, l'analyse serait transformationnelle. Tout cela a contribué à ce que j'accepte en analyse, soit en face à face, soit sur le divan beaucoup de personnes ayant une souffrance limite proche de la psychose, d'autres ayant vécu des traumatismes primaires, souvent cumulatifs, 
des personnes qui ne pouvant pas contenir une douleur épouvantable l'agissaient, etc.

Malgré tout, j'avais confiance en l'analyse, en moi et aux forces de vie de l'analysant; je faisais sans le savoir, de l'analyse avec ce qu'André Green appelle dans son dernier livre les «cas extrêmes». Et ça marchait !

Je remercie mes superviseurs d'alors de m'avoir écoutée, soutenue et fait confiance. J'ai fait des erreurs, certes, mais je crois qu'à cette époque je ne me sois pas rendue compte de toutes celles que je faisais, comparativement à maintenant, vingt et quelques années plus tard.

Avec le temps et les années, il y a eu dé-idéalisation de l'analyse et de l'analyste que je suis, mon sentiment de toute-puissance me fut révélé lorsqu'il diminua, j'ai compris que la psychanalyse a des limites, que les forces transformationnelles de l'analysant ont des limites, que je fais des erreurs dont j'essaie de tirer leçon, que l'humain, la vie et moi avons des limites aussi.

J'ai appris, non la patience que j'ai toujours eue, mais l'endurance, cette endurance à la douleur dont parle si bien et si justement Christian Godbout. L'endurance à la douleur de l'analysant, l'endurance de sa propre douleur, l'une ne va pas sans l'autre, et j'ai acquis un peu de modestie. Certaines paroles de mon analyste me reviennent souvent en tête: "Let's do our best and hope for the best."

La psychanalyse reste à ce jour, pour moi, une aventure extraordinaire, un voyage dans les profondeurs de l'autre et de soi dont on ne connaît jamais l'issue. Elle est devenue maintenant davantage une aventure de solidarité face à la finitude et à face à la vie qui dure jusqu'à sa fin.

Do you want to live until you die?

jacqueline c. prud'homme 4472, rue girouard montréal qc h4a 3e4

\section{Note}

1. Texte présenté à la Société de psychanalyse le 16 janvier 2008. 